Bundesgesundheitsbl -

Gesundheitsforsch - Gesundheitsschutz

2002 $\cdot 45: 139-151 \odot$ Springer-Verlag 2002

Originalien und Übersichtsarbeiten

M. Faulde ${ }^{1}$ R. Fock ${ }^{2} \cdot$ G. Hoffmann ${ }^{3} \cdot$ M.Pietsch ${ }^{4}$

${ }^{1}$ Zentrales Institut des Sanitätsdienstes der Bundeswehr Koblenz $\cdot{ }^{2}$ Robert Koch-Institut, Berlin

${ }^{3}$ Umweltbundesamt, Berlin · ${ }^{4}$ Abt. Hygiene und Umweltmedizin, Universität Mainz

\title{
Tiere als Vektoren und Reservoire von Erregern importierter lebensbedrohender Infektions- krankheiten
}

\section{Zusammenfassung}

Erreger lebensbedrohender und zugleich hochkontagiöser viraler und bakterieller Infektionskrankheiten können nicht nur durch den Menschen selbst, sondern - je nach Erregerspezies - unter anderem durch infizierte Reservoirwirte und tierische Vektoren nach Deutschland eingeschleppt werden. Insbesondere Nagetiere als Reservoire und vektorielle Gliedertiere sind besonders durch den See- und den Luftverkehr global zu verschleppen. Während das Management und die Kontrolle durch den Menschen importierter lebensbedrohender Infektionskrankheiten in Deutschland ein funktionsfähiges Handlungsniveau erreicht hat und derzeit Prüfungen für die Listung geeigneter Mittel und Verfahren zur Flugzeugentwesung stattfinden, werden Inspektionen und Bekämpfungen von Gesundheitsschädlingen, die z.B.über kontainerisierte Güterlieferungen auf dem Seeweg eingeschleppt werden, gegenwärtig nicht durchgeführt. Wegen der Seltenheit des Auftretens solcher Krankheiten sind konkrete Handlungsanweisungen für Schädlingsbekämpfer, Desinfektoren und medizinisch-entomologisches Fachpersonal notwendig, um wirksam einer Weiterverbreitung des Erregers, vor allem seiner Etablierung, entgegenwirken zu können. Zu entwickeln sind konkrete Überwachungs- und Schutzvorkehrungen sowie präzise Verfahrensbeschreibungen.

\section{Schlüsselwörter}

Virusbedingte hämorrhagische Fieber .

Zoonosen · Vektorassoziierte

Infektionserkrankungen .

Vektorenbekämpfung · Öffentlicher

Gesundheitsdienst

$D$ erzeit ist global eine Ausbreitungstendenz von alten und neuen Infektionserregern aufgrund multifaktorieller Ursachen zu verzeichnen $[1,2]$. Der nationale Sicherheitsrat der Vereinigten Staaten von Amerika befasst sich aufgrund einer Direktive des Präsidenten seit 1996 verstärkt mit dieser Thematik. Er schätzt das gesundheitliche Gefährdungsrisiko zumindest für die nächsten $20 \mathrm{Jah}$ re als steigend ein [3]. Auch in Deutschland wurden die Einschleppungsgefährdung sowie das Management und die Kontrolle von lebensbedrohenden hochkontagiösen Infektionskrankheiten umfassend diskutiert $[4,5]$. Als Folge davon befinden sich gegenwärtig überregionale Behandlungs- und Kompetenzzentren in der Planung bzw. im Aufbau. Ihr Ziel ist es, die professionelle und spezifische Versorgung von Patienten, die mit den entsprechenden Erregern infiziert sind, in logistischer, diagnostischer und klinischer Hinsicht zu gewährleisten [6].
Bei den als lebensbedrohend und hochkontagiös definierten Erregern handelt es sich um Erreger von viralen hämorrhagischen Fiebern (VHF), Ausnahme: virusbedingte Affenpocken sowie bakterielle Lungenpest. Folgende Krankheiten werden durch diese Erreger verursacht $[4,5]$ :

D Affenpocken,

- Argentinisches Hämorrhagisches Fieber,

D Bolivianisches Hämorrhagisches Fieber,

D Brasilianisches Hämorrhagisches Fieber,

- Ebola-Fieber,

D Krim-Kongo-Hämorrhagisches Fieber,

- Lassa-Fieber,

D Lungenpest,

D Marburg-Krankheit,

D Omsker Hämorrhagisches Fieber,

Difttal-Fieber und

D Venezuelanisches Hämorrhagisches Fieber.

Knobloch [5] bezieht in diese Kategorie auch folgende Krankheiten mit ein:

\section{Dr.Michael Faulde}

Regierungsdirektor, Zentrales Institut des Sanitätsdienstes der Bundeswehr Koblenz, Ltr Laborgruppe Medizinische Zoologie, Postfach 7340, 56065 Koblenz

E-Mail:fauldem@bwb.org 
Bundesgesundheitsbl -

Gesundheitsforsch - Gesundheitsschutz

2002 · 45:139-151 ๑ Springer-Verlag 2002

\section{Faulde $\cdot$ R. Fock $\cdot G$. Hoffmann \\ M. Pietsch}

\section{Vectors and Animal Reservoirs of Pathogens of Imported Life-Threatening Human Infectious Diseases}

\begin{abstract}
Pathogens of life-threatening and simultaneously highly contagious viral and bacterial human infectious diseases might be brought into Germany from foreign countries not only by infected humans, but also by infected arthropod and rodent vectors and/or animal hosts and reservoir animals. Especially peridomestic and commensal rodent and arthropod vector species have been proven to spread globally, mainly by unintended transport via ship or aircraft after infestation of the transport device. While management and control of life-threatening disease agents brought in by humans recently reached a functional working level, and evaluation of effective aircraft disinsection methods are currently under investigation aiming at licensing suitable products for vector control, no coordinated countermeasures were implemented so far to monitor and control vector species brought in by international travel and commerce e.g. by shipping via containerized crop products. Due to the rare occurrence in Germany of these diseases associated with a high case fatality rate standardized reaction schemes are necessary to prevent the further spreading of the most highly contagious agents. Therefore, disease monitoring and preventive medical strategies have to be developed and implemented, thus integrating the professional expertises of medical entomologists, pest control operators, and disinfectors.
\end{abstract}

\section{Keywords}

Viral haemorrhagic fevers - Zoonoses . Vector-borne diseases - Vector control . Public health

\section{Originalien und Übersichtsarbeiten}

D Dengue Hämorrhagisches Fieber,

D Hantavirus Pulmonales Syndrom,

D Hämorrhagisches Fieber mit renalem Syndrom,

D Lungenmilzbrand.

Wegen ihrer Übertragbarkeit von Mensch zu Mensch erfordern mehrere der genannten Krankheiten - neben einer Intensivtherapie und/oder Intensivpflege - eine besondere Isolierung bzw. Absonderung der Erkrankten, Krankheits- bzw. Ansteckungsverdächtigen sowie eine intensive Suche, Feststellung und Überwachung der Kontaktpersonen [4]. Die Gefahr, dass eine derartig infizierte Person in Deutschland zur Krankenhausaufnahme kommt, wird derzeit als gering angesehen [5]. Dennoch belegen die vier im Jahre 2000 aus Deutschland, den Niederlanden und Großbritannien gemeldeten Fälle von Lassa-Fieber die reale Gefährdung durch den Import von VHF [7]. Um eine für Deutschland flächendeckende professionelle Handlungsgrundlage bei Import von VHF-Patienten bereit zu stellen, schlug die Arbeitsgruppe Seuchenschutz den Aufbau überregionaler Behandlungs- und Kompetenzzentren vor $[4,8]$. Diese sollen die spezifische mikrobiologische Diagnostik mit dem Sicherheitsstandard S-4 (Virologie) bzw. S-3 (Bakteriologie) vorhalten. Eine enge Zusammenarbeit entsprechend ausgestatteter ziviler und militärischer Fachstellen wird dabei als unabdingbar angesehen $[4,8]$.

Während das Management sowie die Kontrolle importierter lebensbedrohender hochkontagiöser Infektionskrankheiten mit den komplett eingerichteten bzw. sich derzeit im Aufbau befindlichen Behandlungs- und Kompetenzzentren in Hamburg, Berlin, Leipzig, Frankfurt am Main und München im Hinblick auf die Versorgung VHF-erkrankter Patienten ein funktionsfähiges Handlungsniveau erreicht hat, ist die Problematik der simultanen Einschleppung VHF-infizierter Vektoren und Reservoirtiere bisher nicht angesprochen worden. Da in erster Linie der VHF-Erkrankte im Blickfeld des Handelns steht, war die Frage des Erregerursprungs bislang sekundär. Gleichwohl können z. B. durch Tourismus, Tiertransporte oder Güterverkehr auch mit lebensbedrohenden hochkontagiösen Erregern infizierte Reservoirtiere und Vektoren nach Deutschland eingeschleppt wer- den, die je nach Vektoreneigenschaft und -kompetenz die assoziierten Erreger auf Mensch und/oder Tier weiter übertragen können [9].

Der Gesetzgeber hat bereits $1961 \mathrm{mit}$ dem Bundes-Seuchengesetz (BSeuchG) ( $\$ \$ 13$ und 41; später 10c), dem dieses Gesetz seit dem 1.1.2001 ablösenden Infektionsschutzgesetz (IfSG) ( $\$ \$ 17$ und 18), mit dem Gesetz zu den Internationalen Gesundheitsvorschriften (IGV) vom 25.7.1969 sowie den aufgrund dieser Gesetze erlassenen Verordnungen der Länder bzw. Durchführungsbestimmungen hinreichende Grundlagen zur Beherrschung jeglicher Vektorsituation geschaffen. Ergänzt werden diese Rechtsvorschriften durch entsprechende Rechtssetzungen auf dem Feld der Veterinärmedizin, die den Schutz vor Zoonosen bzw. Lebensmittel-assoziierten Infektionen betreffen. Auch der hohe Sicherheitsstandard in der Tierkörperbeseitigung trägt wesentlich zur Abwehr von Zoonosen bei.

Um die Gefährdung durch lebensbedrohende hochkontagiöse Infektionserkrankungen des Menschen in seiner epidemiologisch-infektiologischen Gesamtheit qualitativ und quantitativ analysieren zu können und gleichzeitig die Grundlage für eine effiziente und effektive Infektkettenunterbrechung von Naturherden und/oder Vektoren mit Entwesungsmitteln und -verfahren nach $\$ 18$ Infektionsschutzgesetz zu gewährleisten, ist die exakte Kenntnis aller möglichen Infektionswege ausgehend z. B. von einem Naturreservoir oder einem tierischen Überträger zum Menschen hin erforderlich [9].

Ziel dieser Arbeit ist es darzulegen, ob und wie das genannte Erregerspektrum mit Vektoren und Tierreservoiren assoziiert ist, welche Einschleppungswege der Erreger nach Deutschland - außer über den infizierten Menschen - zusätzlich möglich und zu berücksichtigen sind und welche Anforderungen an die Schädlingsüberwachung und -bekämpfung im Rahmen der Infektionskettenunterbrechung gestellt werden müssen.

\section{Assoziation pathogener Erreger mit tierischen Vektoren sowie Tierreservoiren}

Bei näherer Betrachtung der mit den vorgenannten Infektionskrankheiten assoziierten Erreger wird deutlich, dass es 
sich hierbei ausnahmslos um Zooanthroponosen handelt. Krankheiten also, die entweder direkt vom natürlichen Tierreservoir oder über einen zusätzlich dazwischen geschalteten Vektor übertragen werden. Für die genaue Kenntnis der gesamten Infektionskette ist es sehr wichtig zu wissen, wie sich die einzelnen Bestandteile zueinander verhalten, $d . h$. wie der Erreger mit natürlichen und anderen suszeptiblen Reservoiren und ggf. mit aktiven oder passiven Vektoren vergesellschaftet ist, welches die einzelnen Komponenten des Gesamtübertragungsmechanismus sind, wie sich der Erreger in den entsprechenden Wirten verhält, auf welchem Wege der Erreger schließlich auf den Menschen gelangt und welche nicht an den Vektor oder den Wirt gebundenen Faktoren in welchem Ausmaß die Ausbreitung der Vektoren und der Erreger in vormals nicht endemische Gebiete bzw. Nischen begünstigen. Ein Beispiel für letztgenanntes Prinzip ist die Nordwärtswanderung der Schildzecke Ixodes ricinus (Holzbock) [10].

Eine Übersicht über die mit den gefährlichen Erregern assoziierten Tierreservoire und hämophagen (blutsaugende) Vektoren, ihr Vorkommen und ihre Pathogenität, einschließlich der möglichen Einschleppungsgefährdung und des Ausbreitungsrisikos von Reservoir und/oder Vektor in Deutschland ist der Tabelle $1 \mathrm{zu}$ entnehmen.

\section{Übertragung viraler Erreger aus Tierreservoiren}

Interessanterweise sind von den oben genannten zwölf Erregern gefährlicher viraler hämorrhagischer Fieber (VHF) insgesamt sieben Erreger mit Ratten und Mäusen als Primärwirte bzw. Primärreservoire assoziiert, die den Erreger selbst passiv übertragen können. $\mathrm{Zu}$ diesen Erregern zählen die Erreger der bislang bekannten humanpathogenen amerikanischen VHF (Arenaviren), das afrikanische Lassavirus (Arenavirus) sowie die hämorrhagisches Fieber hervorrufenden Altwelthantaviren (Genospezies Hantaan, Dobrava, Seoul) (Bunyaviridae). Die das Hantavirus Pulmonale Syndrom hervorrufenden Neuwelthantaviren der Genospezies Sin Nombre, New York, Black Creek Canal, Bayou und Andes zeichnen sich nicht durch Krankheitsverläufe mit Hämorrhagien, sondern durch eine schwere atypische
Pneumonie aus. Sie haben aber aufgrund ihrer hohen Letalitätsrate von $\geq 45 \%$ besondere Bedeutung.

Im natürlichen Nagetierwirt rufen diese Viren eine chronische Virämie und/ oder Virurie hervor. Primär wird die Infektion über direkten Kontakt mit infizierten Nagetieren, deren Speichel, Urin oder Kot bzw. über infektiösen Exkretstaub übertragen. Hierbei spielt vor allem die Eigenschaft der Mikromiktion, d. h. die kontinuierliche Abgabe feinst verteilten Urins in Abhängigkeit vom Grad des Synanthropismus (zusammen mit dem Menschen lebend) und Kommensalismus (Kommensale: „Tischgenosse“, d.h. Lebewesen in Gemeinschaft mit einem Wirt, von dem es Nahrung beansprucht, deren Entzug den Wirt nicht direkt schädigt) der Reservoirmäuse eine entscheidende Rolle bei der passiven Keimübertragung auf den Menschen [9]. Je enger das Nagerreservoir mit dem direkten Umfeld des Menschen assoziiert ist, desto eher treten die gefürchteten urbanen Transmissionszyklen auf. Dies erhöht das epidemische Ausbreitungsrisiko signifikant. Es ist daher entscheidend, die Bionomie (genaue Kenntnis der Lebensweise von Organismen in ihrer Abhängigkeit von der Umwelt) der natürlichen Erregerreservoire und die Wirtsspezifitäten des Erregers auch in seinen Feinheiten exakt zu kennen, um Präventionsmaßnahmen sowie Infektionskettenunterbrechungsmaßnahmen unter Anwendung von sicher tilgend wirksamen Schädlingsbekämpfungsmitteln in kürzester Zeit und mit maximaler Wirksamkeit durchführen zu können. Aus den primären Nagetierreservoiren kann der Erreger unter bestimmten Bedingungen zudem auf Populationen anderer, kommensaler bzw. synanthroper Schadnager übergehen, z.B. das Juninvirus auf die Hausmaus, Mus musculus. Dies kann zu einer Verlagerung des Transmissionsmodus aus dem sylvatisch/ruralen (Wald/Land) in den urbanen Bereich und damit zu einer epidemischen Ausbreitung führen [11]. Veränderungen in der Umwelt sowie neue landwirtschaftliche Methoden können einen großen Einfluss auf die Inzidenz dieser „Roboviren" (Rodent-borne Viruses) haben. So werden jährlich zwischen mehreren hundert bis zu 3500 Fälle von Argentinischem Hämorrhagischen Fieber diagnostiziert. Das diese Erkrankung verursachende Juninvirus war unbekannt, bis in der südamerikanischen Pampas großflächig Mais angebaut wurde und sich das natürliche Erregerreservoir, die Maus Calomys musculinus, über Befall gelagerter Maisvorräte explosiv vergrößern konnte. Über die neuen kommensalen Verhaltenseigenschaften dieser Maus kam der Mensch vermehrt mit dem Erreger in Kontakt [12].

Hämophage Arthropoden (blutsaugende Gliedertiere) spielen nach bisherigen Erkenntnissen bei der primären Übertragung von „Roboviren“ keine oder nur eine sehr untergeordnete Rolle, obwohl gelegentlich der Virusnachweis in hämophagen Milben gelang (z. B. Juninvirus, Hantaanvirus) [13]. Sekundär sind die genannten Arenaviren insbesondere auch nosokomial von Mensch zu Mensch übertragbar, was zur Klassifikation in die entsprechende Sicherheitsstufe beigetragen hat [14]. Infektionen im Rahmen von Labortätigkeiten sind ebenso bekannt. Bei Hantaviren ist eine Übertragung von Mensch zu Mensch noch nicht gesichert und tritt wenn, dann nur sehr selten auf (Genospezies Andes) [15]. Humanpathogene Hantaviren der Genospezies Puumala und Dobrava sind in Deutschland endemisch, und auftretende Erkrankungsfälle werden nach Implementierung des Infektionsschutzgesetzes seit Januar 2001 dem Robert KochInstitut gemeldet. Die mit Ratten assoziierte, global verbreitete Genospezies Seoul wurde in Deutschland bislang noch nicht nachgewiesen [11]. Erste Hinweise sprechen weiterhin dafür, dass Hantaviren auch durch hämophage Laufmilbenlarven der in Ostasien endemischen Gattung Leptotrombidium [16] sowie durch die Tropische Rattenmilbe Ornithonyssus bacoti [17] übertragen werden können.

\section{Übertragung viraler Erreger über infizierte Vektoren}

Drei weitere VHF-Erreger (Krim-Kongo-Hämorrhagisches Fiebervirus, Rifttalfieber-Virus und Omsker Hämorrhagisches Fiebervirus), die verschiedenen Virusgattungen angehören, treten aufgrund ihrer Wirtseigenschaften auch oder überwiegend in Klein- und Schadnagern auf. Sie werden in der Regel jedoch nicht durch diese selbst, sondern durch blutsaugende Gliedertiere auf den Menschen übertragen. In diesem Fall kann durch Kleinnager lediglich die Reservoir-, nicht aber die Vektorfunktion 


\section{Originalien und Übersichtsarbeiten}

Tabelle 1

Reservoirtiere und tierische Vektoren von lebensbedrohenden hochkontagiösen Infektionserregern

Errege

Erkrankung

Vorkommen

Letalitätsrate

Vermutete bzw.

belegte

Inzidenz/Jahr

\begin{tabular}{|c|c|c|c|c|}
\hline Affenpocken-Virus & Humane Affenpocken & $\begin{array}{l}\text { West- und Zentralafrika, } \\
\text { hauptsächlich Zaire }\end{array}$ & $10-15 \%$ & $<100$ \\
\hline Junin-Virus; Oliveros-Virus & $\begin{array}{l}\text { Argentinisches Hämorrhagisches } \\
\text { Fieber }\end{array}$ & Argentinien & $5-30 \%$ & $100-3500$ \\
\hline Machupovirus & $\begin{array}{l}\text { Bolivianisches Hämorrhagisches } \\
\text { Fieber }\end{array}$ & Bolivien & $5-30 \%$ & $<100$ \\
\hline Sabia-Virus & $\begin{array}{l}\text { Brasilianisches Hämorrhagisches } \\
\text { Fieber }\end{array}$ & Brasilien & $5-30 \%$ & $<100$ \\
\hline Dengue-Virus & Dengue-Hämorrhagisches Fieber & $\begin{array}{l}\text { >100 Länder in Asien, Afrika, } \\
\text { Süd- und Mittelamerika, } \\
\text { Nordaustralien }\end{array}$ & $\begin{array}{l}\text { Bei DHF/DHSS: } \\
<5-50 \%\end{array}$ & $\begin{array}{l}>50 \text { Mio.; davon } \\
\text { ca. } 500.000 \text { DHF/ } \\
\text { DHSS-Fälle }\end{array}$ \\
\hline Ebola-Virus & Ebola-Fieber & $\begin{array}{l}\text { Zentralafrika, insbes. Sudan, } \\
\text { Zaire, Kenia, Uganda }\end{array}$ & $53-88 \%$ & $\begin{array}{l}<100 \text { bis }>300 \\
\text { während Ausbrüchen }\end{array}$ \\
\hline $\begin{array}{l}\text { Hantavirus Genospezies } \\
\text { a) Sin Nombre; } \\
\text { b) Andes und weitere }\end{array}$ & $\begin{array}{l}\text { Hantavirus Pulmonales Syndrom } \\
\text { (HPS) }\end{array}$ & Nord-, Mittel- und Südamerika & $45-60 \%$ & $\begin{array}{l}\text { Unklar; } \\
\text { wahrscheinlich }<100\end{array}$ \\
\hline $\begin{array}{l}\text { Hantavirus Genospezies } \\
\text { a) Hantaan } \\
\text { b) Dobrava } \\
\text { c) Seoul }\end{array}$ & $\begin{array}{l}\text { Hämorrhagisches Fieber mit } \\
\text { renalem Syndrom (HFRS) }\end{array}$ & Asien, Europa & $8-15 \%$ & $150.000-200.000$ \\
\hline $\begin{array}{l}\text { Krim-Kongo-Hämorrhagisches } \\
\text { Fieber-Virus }\end{array}$ & $\begin{array}{l}\text { Krim-Kongo-Hämorrhagisches } \\
\text { Fieber }\end{array}$ & Asien, Europa, Afrika & $10-50 \%$ & $\begin{array}{l}\text { Unklar } \\
\text { Vermutlich >>100 }\end{array}$ \\
\hline
\end{tabular}

\begin{tabular}{|c|c|c|c|c|}
\hline Lassa-Virus & Lassa-Fieber & $\begin{array}{l}\text { Afrika südl. der Sahara, } \\
\text { hauptsächlich Nigeria, } \\
\text { Liberia, Sierra Leone }\end{array}$ & Са. $15 \%$ & $300.000-500.000$ \\
\hline Bacillus anthracis & Lungenmilzbrand & $\begin{array}{l}\text { Weltweit, selten in } \\
\text { Industrienationen }\end{array}$ & $\begin{array}{l}\text { Bei Lungenmilz- } \\
\text { brand meist 100\% }\end{array}$ & $\begin{array}{l}\text { Lungenmilzbrand } \\
\text { vermutlich }<100\end{array}$ \\
\hline Yersinia pestis & Lungenpest & $\begin{array}{l}\text { Erreger in } 23 \text { Ländern in Asien, } \\
\text { Afrika und Amerika, } \\
\text { selten Europa } \\
\text { endemisch }\end{array}$ & $\begin{array}{l}\text { bei Lungenpest } \\
100 \%\end{array}$ & $\begin{array}{l}200-6.000 ; \\
\text { Lungenpest }<100\end{array}$ \\
\hline Marburg-Virus & Marburg-Fieber & Zentral und Südafrika & Са. $25 \%$ & $<100$ \\
\hline
\end{tabular}




\section{Reservoirtiere/passive Vektoren}

Eichhörnchen der Gattungen

Funisciurus und Heliosciurus

Verschiedene Mäusespezies, insbesondere Akodon azarae; Calomys musculinus;

Bolomys obscurus

Mäuse, insbesondere

Calomys callosus

Mäuse der Gattung Calomys

Mensch, Affen

Primäres Reservoir unbekannt Sekundär Makaken

(Maccaca fasciularis)

a) Peromyscus maniculatus (Weißfußmaus)

b) Oligoryzomys longicaudatus; Calomys laucha u.v.a.

a) Apodemus agrarius (Brandmaus)

b) A. flavicollis (Gelbhalsmaus) c) Rattus rattus (Hausratte);

R. norwegicus (Wanderratte)

Nagetiere, Insektivoren, Schafe, Rinder, Ziegen, Schildzecken

Primär Praomys natalensis

(Erdratte)

Sekundär weitere Nagetierarten

Verschiedenste Säugetiere

Wildnager und andere Kleinsäuger

Primäres Reservoir unbekannt Sekundär Meerkatzen

(Cercopithecus aethiops)
Hämophage Vektoren

Keine bekannt

Keine bekannt

Keine bekannt

Hauptvektoren: Aedes aegypti; Ae. albopictus

Nebenvektoren: Ae. vigilax; Ae. africanus;

Ae. luteocephalus; Ae. furcifer-taylori-Komplex;

Ae.niveus; Ae. scutellaris; Ae. hensilli;

Culex annulirostris; C. bitaeniorhynchus

Keine bekannt

Keine bekannt

(beide Ostasien), Tropische Rattenmilbe

Ornithonyssus bacoti

Hauptsächlich Schildzecken wie

z.B. Hyalomma marginatum-Komplex; aber auch $\mathrm{H}$. truncatum; $\mathrm{H}$. asiaticum;

H. anatolicum; Rhipicephalus sanguineus;

R.turanicus; R. pumilo; Dermacentor marginatus;|xodes ricinus; Lederzecken Argas persicus; Ornithodoros lahorensis; Stechgnitzen der Gattung Culicoides

Keine bekannt
Verschleppungsgefahr

des infizierten

Reservoirtiers/Vektors

Ja

Keines

Ja

Unbekannt

Ja

Ja

Ja

Unbekannt

Ja

Unbekannt und theoretisch möglich

$\mathrm{Ja}$

Alle genannten

Reservoire; zumindest

Dobrava-Virus endemisch

$\mathrm{Ja}$

a

Einige potenzielle Vektorspezies sind bereits endemisch wie Ixodes ricinus, Rhipicephalus sanguineus, Dermacentor marginatus u.a.

usbreitungsrisiko des Reservoirtiers/Vektors in Deutschland

Unbekannt

Unbekannt

Ja

Aedes albopictus wandert derzeit als kälteresistenter Stamm aktiv von Italien und Frankreich aus nach Mitteleuropa ein; hat als nördl. Grenze den Gardasee und die Bretagne erreicht

Unbekannt

Ja Bislang bekannte hämophage Vektoren nicht endemisch

Ja

unbekannt

Ja

Ja

Teilweise endemisch
Passive Übertragung in erster Linie durch alle regurgitierenden Stechfliegen wie Wadenstecher (Stomoxys spp.); Bremsen (Tabanidae); Tsetse-Fliegen (Glossinae), aber auch durch weitere hämophage Vektoren möglich

Ca. 120 Floharten, besonders die Rattenflohspezies Xenopsylla cheopis; X.astia; X. brasiliensis; Pulex irritans (Menschenfloh); Ctenocephalides felis (Katzenfloh);

C. canis (Hundefloh)
Ja

Urbane Reservoire

und Vektoren z.T. endemisch

Nur durch Tiertransport 
Fortsetzung Tabelle 1

Reservoirtiere und tierische Vektoren von lebensbedrohenden hochkontagiösen Infektionserregern

\begin{tabular}{|c|c|c|c|c|}
\hline Erreger & Erkrankung & Vorkommen & Letalitätsrate & $\begin{array}{l}\text { Vermutete bzw. } \\
\text { belegte } \\
\text { Inzidenz/Jahr }\end{array}$ \\
\hline $\begin{array}{l}\text { Omsker Hämorrhagisches } \\
\text { Fieber-Virus }\end{array}$ & Omsker Hämorrhagisches Fieber & Westsibirien & $0,5-3 \%$ & $\begin{array}{l}\text { Unklar } \\
\text { Vermutlich }<100\end{array}$ \\
\hline
\end{tabular}

Rifttal-Fieber-Virus

Rifttal-Fieber

Guanarito-Virus; (Pirital-Virus?)
Venezuelanisches

Hämorrhagisches Fieber

Afrika, Jemen, Saudi-Arabien

Venezuela

$10-20 \%$

$<1 \%$ hämorrhagische

Verläufe, dann Letalität ca. $50 \%$

$<100$
Während Epidemien

bis 100.000 übernommen werden. Die Erregereinschleppung kann bei diesen Krankheiten sowohl durch infizierte Reservoire als auch durch infizierte Vektoren stattfinden.

\section{Krim-Kongo-Hämorrhagisches Fiebervirus}

Das vor allem in Asien und Afrika weit verbreitete Krim-Kongo-Hämorrhagische Fiebervirus (CCHFV), ein Nairovirus, kommt in verschiedensten Säugetierreservoiren wie Schafen, Rindern, Ziegen, Pferden, Nagetieren, Hasenartigen, Insektivoren, Fledermäusen sowie einigen tropischen Vogelspezies natürlich vor $[18,19]$. Experimentell konnte eine Virämie in Hasen, Lepus spp., nachgewiesen werden [18]. Die Übertragung erfolgt in Europa primär über den Stich infizierter Schildzecken (Ixodidae) [18]. Außerhalb Europas kommen als Überträger auch Lederzecken der Gattungen Argas und Ornithodoros sowie Stechgnitzen der Gattung Culicoides in Frage [18]. Hauptvektor ist die Schafzecke Hyalomma marginatum einschließlich ihrer verschiedenen in Europa, Asien und Afrika auftretenden geographischen Subspezies H. m. marginatum, H. m. rufipes und H.m. turanicum. Bei Schildzecken erfolgt die Erregerweitergabe des KrimKongo-Hämorrhagischen Fieberviruses transovariell und transstadial. Eine den natürlichen Viruszyklus zusätzlich erhaltende venerische Transmission wurde ebenfalls nachgewiesen [19]. Zudem kann dieses hochkontagiöse Virus durch engen Kontakt mit infizierten Säugetieren, hauptsächlich über Schafe (z. B. bei Schafscherern und Fleischern), mit infizierten Patienten oder mit zerdrückten, infektiösen Vektorzecken erworben werden. Sekundär erworbene, auch nosokomiale Infektionen sind relativ häufig. Die durchschnittliche Transmissionsrate bei der nosokomialen Infektion beträgt z. B. in Bulgarien „nur“ $6 \%$, ist aber in den meisten anderen Ländern höher $[13,18,20]$.

\section{Rifttalfieber-Virus}

Das Rifttalfieber-Virus (RVF) zeigt derzeit eine erweiterte epidemiologische wie auch geographische Ausbreitung. Durch den El-Nino-Effekt hervorgerufene Regenfälle, die zwischen 6o- und 10ofach über der Norm lagen, führten im Winter 1997/98 in Teilen Tansanias, Kenias und Somalias nach einer explosionsartigen Vermehrung der Stechmückenpopulationen zu einer Rifttalfieber-Epidemie mit mindestens 89.000 humanen Fällen und Viehverlusten bis zu 70\% [21]. Der Erreger lässt sich in den verschiedensten Säugetieren nachweisen, wobei das Virus für Ziegen und Kamele weniger pathogen zu sein scheint, als z. B. für Schafe (Letalitätsrate bei Lämmern bis 90\%). Er wird von zumindest 23 verschiedenen Stechmückenarten aus fünf Gattungen, Stechgnitzen der Gattung Culicoides, Kriebelmücken der Gattung Simulium sowie Schildzecken der Gattung Rhipi- cephalus aktiv übertragen. Die enorme Wirtsunspezifität des Rifttalfieber-Virus und die hohe Erregersuszeptibilität einer ganzen Reihe von Vektorarthropoden führen zu einem extrem komplexen enzootischen (endemisch in Tierreservoir) und epizootischen (veterinärmedizinisch für epidemisch) Transmissionszyklus [22]. Einer der Hauptvektoren, die Hausmücke Culex pipiens, ist mit verschiedenen Subspezies auch in Deutschland endemisch. Es ist derzeit aber unklar, inwieweit das Virus unter den vorliegenden epidemiologisch-klimatischen Bedingungen endemisieren kann. Die für die epidemische Ausbreitung des RVF verantwortlichen Hauptvektoren unterscheiden sich je nach geographischer Region. Dass das Virus unter bestimmten Bedingungen den afrikanischen Kontinent, in dem er bis zu Jahr 2000 ausschließlich endemisch war, z. B. auch über den Mittelmeerraum verlassen kann, zeigt das Beispiel der Rifttalfieber-Epidemien im Jemen sowie in Saudi-Arabien. Erstmals außerhalb Afrikas auftretend [23, 24], wurden im Jahr 2000 im Jemen offiziell 1087 Verdachtsfälle einschließlich 121 Todesfällen festgestellt [25]. In den benachbarten Regionen Saudi-Arabiens waren es in diesem Zeitraum offiziell 884 Verdachtsfälle mit 124 Todesfällen [26]. Offensichtlich ist das Virus über infiziertes Nutzvieh, insbesondere Schafe und Ziegen, aus den Endemiegebieten Kenias und Somalias über Djibouti zunächst in den Jemen und von dort aus nach Saudi-Arabien 
Reservoirtiere/passive

Vektoren

Kleinsäuger, insbesondere

Kleinnager, Ostschermaus

(Arvicola terrestris) und

Bisamratte (Ondrata zibethicus),

Schildzecken

Verschiedenste Säugetiere

Mäuse, insbesondere

Sigmodon alstoni;

Zygodontomys brevicauda
Hämophage Vektoren

Schildzecken, insbesondere

Dermacentor marginatus, D. reticulatus

und D. apronophorus

Vektorkompetente Dermacentor-Zecken

>23 Stechmückenarten verschiedener

Gattungen wie Culex spp. (besonders

Culex pipiens-Komplex); Aedes spp.;

Anopheles spp.;Stechgnitzen der Gattung

Culicoides, u.a.

Keine bekannt
Verschleppungsgefahr

des infizierten

Reservoirtiers/Vektors

Ja

endemisch

Ausbreitungsrisiko

des Reservoirtiers/Vektors

in Deutschland

Ja

Ja

Vektoren teilweise endemisch

(Culex pipiens-Komplex) bzw. saisonal

endemisierbar

Ja

Unbekannt eingeschleppt worden [27]. Die dortigen vektorkompetenten Stechmückenspezies haben daraufhin die Infektionskette über die infizierten Tierreservoire auf den Menschen schließen können.

\section{Omsker Hämorrhagisches Fiebervirus}

Das zu den Flaviviren gehörende Omsker Hämorrhagische Fiebervirus (OHFV) kommt hauptsächlich in den Steppengebieten Westsibiriens vor und ist sehr eng mit dem Erreger der Kyasanur Waldkrankheit, dem Kyasanur Forest Disease Virus, verwandt. Als Reservoire für das OHFV sind hauptsächlich Ostschermäuse, Bisamratten, aber auch Mäuse, Ratten und Spitzmäuse sowie Schildzecken bekannt. Letztere tragen durch transovarielle Übertragung des Erregers zur Erhaltung des natürlichen Zyklus bei. Vornehmlich wird das Virus vektoriell durch die Schafzecken Dermacentor marginatus und D. reticulatus übertragen. Nach neueren Erkenntnissen ist das OHFV aber auch durch direkte Transmission von der Bisamratte auf den Menschen (Bisamrattenjäger) sowie über kontaminiertes Wasser und durch Laborinfektionen übertragbar [13, 28, 29]. Neben der im Pflanzenschutz in unseren Gebieten häufig schädlichen Ostschermaus (Arvicola terrestris) sind nach Ansiedlung der Bisamratte (Ondatra zibeticus) im Jahre 1905 bei Prag und nahezu landesweiter Ausbreitung in Deutschland sowohl beide Hauptreservoire als auch die beiden Hauptzeckenvektoren ende- misch. Die Schildzecke Dermacetor reticulatus wurde anscheinend im 20. Jahrhundert nach Deutschland eingeschleppt und breitet sich seit den 7oer-Jahren in Süddeutschland rasch aus, wobei sich bereits fokal ein stabiler, neu endemisierter Infektionszyklus der Hundebabesiose in den Räumen Kehl/Offenburg/Lahr/ Emmendingen/Freiburg i.Br. etabliert hat $[30,31]$. Einer künftigen Etablierung des OHFV in Deutschland steht nach Erregereinschleppung hinsichtlich Reservoir- und Vektorvorkommen nichts im Wege.

\section{Ungeklärte Übertragungsmodi von Filoviren}

\section{Marburg- und Ebola-Viren}

Die hochpathogenen, zu den Filoviren gehörenden Marburg- und Ebola-Viren scheinen seit ihrer Erstisolation 1967 respektive 1976 häufiger als zunächst erwartet aufzutreten [32]. Das Marburgsowie das Ebola Hämorrhagische Fieber zeichnen sich durch eine hohe Letalitätsrate zwischen 22 bis $88 \%$ aus [32]. Das Naturreservoir beider originär in Zentralafrika endemischen Virusspezies ist trotz aller bisherigen Anstrengungen immer noch unbekannt. Man nimmt jedoch an, dass es sich bei beiden Infektionskrankheiten um Zoonosen handelt. Sekundäre Reservoire, die letztendlich auch zu einer Einschleppung des Marburgbzw. des Ebola-Virus nach Deutschland und Jugoslawien bzw. nach Italien und in die USA geführt haben, sind beim Marburg-Virus Meerkatzen (Cercopithecus aethiops) und beim Ebola-Virus Makaken (Macacca fascicularis) [13, 32, 33]. Das Ebola-Restonvirus, das eine für Makaken tödliche hämorrhagische Erkrankung hervorruft, führte beim Menschen nach allen bisher untersuchten Fällen zu einer asymptomatisch verlaufenden Infektion mit Virämie und Antikörperbildung. Es konnte bisher nur mit einer Affenexportfirma auf den Philippinen in Zusammenhang gebracht werden, wobei ungeklärt ist, ob das EbolaRestonvirus auf den Philippinen endemisch ist, oder vorher aus Afrika eingeschleppt wurde [32]. Filoviren werden nosokomial, von Mensch zu Mensch, neonatal oder durch Kontakt mit infizierten Affen übertragen. Da bei einer Reihe von Fällen der Übertragungsmodus ungeklärt ist, wird zudem eine aerogene Transmission durch Tröpfcheninfektion diskutiert, die bislang lediglich beim Ebola-Restonvirus unter Affen belegt ist [32].

\section{Affenpockenviren}

Nach Eradikation des Pockenvirus konzentriert sich die Aufmerksamkeit auf das mit dem Variolavirus (Poxvirus) verwandte Affenpockenvirus (Orthopoxvirus). Klinischer Verlauf sowie Letalität einer Affenpockeninfektion sind nahezu mit denen des Humanpockenvirus identisch [13]. Zwischen 1970 und 1986 sind über 400 Fälle humaner Affenpocken 
aus Zentralafrika, hauptsächlich Zaire, dokumentiert worden. Die Erkrankung tritt einzeln oder in kleinen Gruppen von wenigen Personen auf. Neuere Daten scheinen dafür zu sprechen, dass sich das Affenpockenvirus auf den Menschen adaptieren könnte, da die Sekundärinfektionsrate von Mensch zu Mensch in jüngster Zeit zugenommen hat [34]. War man bisher der Meinung, dass eine Übertragung von Mensch zu Mensch nur zu einem geringen Prozentsatz nach Kontakt zu Primärfällen auftritt, zeigte der jüngste größere Ausbruch 1996/97 in der Demokratischen Republik Kongo ein anderes epidemiologisches Transmissionsmuster [34, 35]. Von Februar 1996 bis Februar 1997 wurden insgesamt 88 Fälle von Affenpocken aus zwölf Dörfern nachgewiesen, wobei die Mehrzahl der Erkrankungsfälle sekundär akquiriert wurde [35]. Primärreservoir des Affenpockenvirus sind hauptsächlich in Ölpalmenplantagen um die Dörfer lebende Eichhörnchen der Gattungen Funisciurus und Heliosciurus [13,34].

\section{Übertragung bakterieller Erreger}

\section{Yersinia pestis}

Seitens der beiden oben genannten Infektionserkrankungen bakteriellen Ursprungs (Lungenpest, Milzbrand) ist die Reservoireigenschaft von Klein- und Schadnagern für Yersinia pestis von besonderer Bedeutung. Das Pestbakterium kommt zwar überwiegend im sylvatischen Übertragungsmodus (Übertragungsmodus im Wald) bei wald- und steppenbewohnenden, nicht kommensalen Nagetieren vor, kann aber durch Infektion von Populationen synanthroper und kommensaler Schadnager, z. B. Hausratten, direkt in das menschliche Umfeld gelangen und urbane Pestepidemien hervorrufen. Die möglichen Transmissionswege der Pest sind extrem heterogen und komplex, da nicht nur Primär- und Sekundärwirt sowie Vektor, sondern auch der Organkompartimentwechsel im infizierten Wirt von besonderer Bedeutung ist. Neben dem spezifischen Verhalten der Reservoirnager spielt die Bionomie der die Pesterreger aktiv übertragenden Flohspezies eine weitere besondere Rolle. Je enger die Flohspezies mit dem Lebensraum des Menschen vergesellschaftet ist, und je eher sie den Menschen als atypischen
Wirt annimmt, desto eher kann sie am urbanen Transmissionsmodus der Pest teilhaben. Dies trifft insbesondere auf den südlichen Rattenfloh, Xenopsylla cheopis, aber auch auf den Menschenfloh, Pulex irritans, zu. Auch heute noch ist der Pesterreger in 38 Ländern Amerikas, Afrikas und Asiens zumeist in sylvatisch-enzootischen Transmissionszyklen endemisch und tritt mit einer jährlichen Inzidenz von 200 bis 6000 Fällen auf [36]. Bei auftretenden Lungen- und/ oder Bubonenpestepidemien, wie z. B. 1994 in Indien oder 1995 auf Madagaskar, muss die Gefährdung der Verschleppung infizierter Schadnager und/oder Flöhe über Handel und Verkehr durch Überwachungs- und Quarantänisierungsmaßnahmen auf ein vertretbares Minimum gesenkt werden. Epidemiologisch interessant ist eine Adaptierung von Yersinia-pestis-Stämmen aus den USA an Hauskatzen, die nicht mehr grundsätzlich an Pest erkranken, sondern in 62,5\% der Infektionsfälle einen asymptomatischen bzw. abortiven Verlauf aufweisen. $75 \%$ der die Pestinfektion überlebenden Hauskatzen waren infektiös. Über infektiöse Katzen mit asymptomatischem Krankheitsverlauf kann das Pestbakterium anschließend durch Biss, Kratzen, etc. direkt auf den Menschen übertragen werden, der naturgemäß einen sehr engen Kontakt zu Haustieren hält [37]. Da bei diesem Transmissionsmodus über Hauskatzen die spezifische Therapie oftmals zu spät einsetzt, beträgt die Letalitätsrate beim Menschen in den USA 16\% $[37,38]$ im Gegensatz zu 8,7\% im Verlaufe der Bubonenpestepidemie auf Madagaskar 1995 [39]. Dies stellt ein aktuelles Beispiel dafür dar, dass Evolutions- und Selektionsmechanismen von Infektionserregern kontinuierlich weiter laufen und ständig beobachtet und dokumentiert werden müssen. Die gefürchtete hochkontagiöse Lungenpest tritt natürlich erst im Verlaufe einer primär akquirierten, flohübertragenen Bubonenpestepidemie durch Kompartimentwechsel vom Lymphsystem über die bakteriämische Streuung in die Lunge des infizierten Menschen sekundär auf.

\section{Bacillus anthracis}

Anthrax ist eine weit verbreitete Zoonose von Nutz- und Wildtieren. Epidemiologisch lassen sich in eine industrielle und eine nicht-industrielle Übertra- gungsform differenzieren. Die industrielle Form manifestiert sich beim Menschen zumeist in der kutanen, gelegentlich jedoch auch in der pulmonalen $\mathrm{Ma}$ nifestation durch Kontakt mit zu verarbeitenden infektiösen Tierbestandteilen wie Haare und Felle sowie durch Kontakt mit verseuchtem Erdboden aber auch Schlachttieren bzw. von diesen gewonnenen Produkte. Letztere kommt bei der industriellen Übertragungsform erheblich häufiger vor, als bei der nicht-industriellen, die hauptsächlich über Kontakt mit lebenden infizierten Tieren akquiriert wird. Aufgrund des Transportes inhalierter Sporen durch Makrophagen in das lymphatische System führt Lungenmilzbrand nach Septikämie rasch zum Tode [40]. Die Bacillus-anthracis-Sporen mit sehr hoher Tenazität (Widerstandsfähigkeit) lassen sich effizient auch durch passive Vektoren und Vehikel wie kontaminierte Erde und Wasser übertragen $[9,40]$, wobei eine Weiterverbreitung von B. anthracis-Sporen und/oder -Bakterien durch Fliegen vor allem blutsaugende Fliegen und Schmeißfliegen (Calliphoridae) unter bestimmten Voraussetzungen möglich und experimentell belegt ist [41]. Eine Übertragung von Mensch $\mathrm{zu}$ Mensch ist extrem selten $[13,40]$.

\section{Einschleppungsmöglichkeiten pathogener Erreger}

Mit Stand 2000 waren 1709 humanpathogene Erreger bekannt, von denen 832 (49\%) Zoonosen verursachen. Von den 1709 Erregern wiederum sind 156 als aktuell wiederauflebend („emerging“) klassifiziert worden. Von diesen wiederauflebenden 156 Infektionskrankheiten sind 114 (73\%) Zoonosen [42]. Bezüglich der lebensbedrohenden hochkontagiösen Erreger von Zooanthroponosen wird in der Fachliteratur im Sinne der „emerging diseases“ ein häufigeres Auftreten von Affenpocken, Argentinischem Hämorrhagischen Fieber, Dengue Hämorrhagischem Fieber, Ebolafieber, Hantavirosen, Lassafieber, Marburgfieber, Rifttalfieber und Pest postuliert. In diesem Zusammenhang können drei verschiedene Gruppen von Infektionskrankheiten differenziert werden [43]:

D Krankheiten, die erst in den letzten vier Jahrzehnten auftauchten („emerging diseases“), 
D Krankheiten, die unter Kontrolle schienen und jetzt wieder vermehrt auftreten („resurging diseases“) und

D Krankheiten, die sich in Gebiete ausbreiten, in denen sie bislang nicht endemisch waren („introduced diseases“).

Die Gründe für die gegenwärtige, global zu verzeichnende Ausbreitungstendenz von Infektionskrankheiten sind multifaktoriell und insbesondere abhängig von den folgenden Faktoren $[1,3,9]$ :

Deränderungen in den Sozialstrukturen,

D globales Bevölkerungswachstum,

D steigendes Migrationsverhalten,

D Veränderungen in den Gesundheitssystemen,

D exzessiver Gebrauch von Antibiotika,

D sinkende Durchimpfungsraten und Einstellen von Impfstoffproduktionen,

D steigende Anzahl immunsupprimierter Patienten,

Dlobalisierung von Nahrungsmittelproduktion, -verarbeitung und -verteilung,

D Veränderungen im menschlichen Verhalten wie verstärkte Reisetätigkeiten etc.,

D Umweltveränderungen, die zu Habitat- und Klimaänderungen mit häufigen Dürre- und Flutkatastrophen oder zur Schaffung von neuen Entwicklungsnischen für Vektoren und Reservoirtiere führen,

D fortschreitender Zerfall staatlicher Gesundheitssysteme bzw. Eingriffe durch fachlich nicht entsprechend qualifizierte Administratoren in Maßnahmenplanungen und -abläufe,

D Mutations-, Selektions- und Adaptierungsprozesse innerhalb der Mikroorganismen, Vektoren und Reservoire,

D zunehmende Urbanisierungstendenzen von Vektoren und Reservoiren sowie

D Wegfall von spezifischen Ausbildungen und Referenzstellen z. B. zur gesundheitlich orientierten Schädlingsbekämpfung sowie zur Ektoparasitologie und Vektorwissenschaft.

Hinsichtlich der Ausbreitungsprinzipen vektorassoziierter Infektionserkrankungen lassen sich die aktive und die passive Ausbreitung unterscheiden. Bei der aktiven Ausbreitung verbreiten sich Er- reger, Vektor, Vektor + Erreger, Reservoirmedien (Tiere, Lebens- oder Futtermittel etc), Reservoirmedien + Erreger oder Erreger + Vektor + Reservoirmedien selbstständig aus. Im Gegensatz dazu findet bei der passiven Ausbreitung eine Verschleppung der genannten Bestandteile der Infektionskette durch verschiedenste Transportmedien statt. Eine Übersicht über die wichtigsten Faktoren, die zur aktiven bzw. passiven Ausbreitung führen gibt Abb. 1 .

Während die aktiven Ausbreitungsmechanismen nur durch Monitoringmaßnahmen überwachbar und nur in Sonderfällen steuerbar sind, kann bei allen passiven Ausbreitungsmechanismen, die anthropogenen Ursprungs sind, direkt durch verschiedene ein- und verschleppungsverhindernde sowie -minimierende Maßnahmen eingegriffen werden. Beim Management im Fall der Einschleppung gefährlicher Erreger durch infizierte menschliche Reservoire sind die notwendigen Risikoanalysen bereits durchgeführt worden und der Aufbau von Kompetenz- und Behandlungsstrukturen ist weit fortgeschritten. Ähnliches gilt für Nutztierreservoire bzw. mit gefährlichen Erregern infizierte Nutztiere. Hier werden tierseuchenrechtliche Bestimmungen wie Quarantänierung und andere tierseuchenpräventive Maßnahmen mittels vorhandener Strukturen (z.B. Veterinär- und Lebensmitteluntersuchungsämter sowie Tiergesundheitsdienste) umgesetzt.

Anders ist die Situation bei der Einschleppung infizierter Vektoren oder Tier-

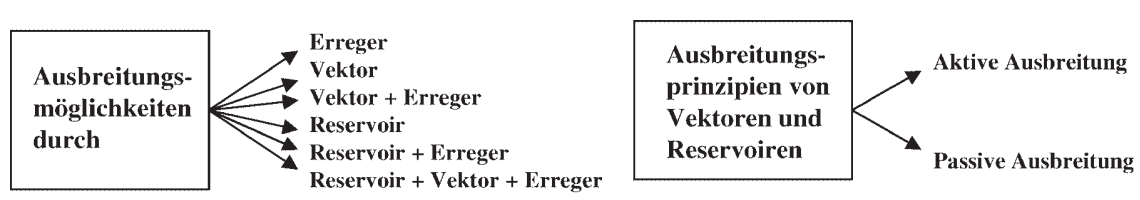

reservoire vor allem aus der Gruppe der kommensalen und/oder synanthropen Ratten und Mäuse. Diese Einschleppung kann durchaus gemeinsam mit dem infizierten Menschen oder Nutztier erfolgen. Besonders geeignet für die Einschleppung von Vektoren und Reservoiren von Tieren aus der Klasse der Arthropoden und der Ordnung der Nagetiere sind der Luft- sowie der Seeverkehr. Die „Markererkrankung“ für eine tatsächlich stattgefundene Einfuhr infizierter hämophager Vektoren ist die Flughafen- und Seehafenmalaria [44]. Zuerst im Jahre 1977 beschrieben, sind bis Ende 1997 insgesamt 63 sichere Fälle der verschiedenen Formen der Flughafenmalaria allein aus Europa publiziert worden [44]. Wohl aufgrund der globalen Häufigkeit der Malaria mit einer jährlichen Inzidenz von 300 bis 500 Millionen Fällen und den einfachen, überall verfügbaren diagnostischen Nachweismöglichkeiten fällt ein Import dieser Krankheit mit großer Wahrscheinlichkeit auf.

\section{Einschleppungen über den Flugverkehr}

Mit welcher Wahrscheinlichkeit z. B. Fälle einer durch exotische Erreger hervorgerufenen viralen Flughafenenzephalitis oder ein autochthon in Deutschland akquiriertes Flughafen-Rifttalfieber diagnostiziert würde, ist derzeit unklar. Untersuchungen belegen, dass vektorkompetente Stechmückenspezies unter anderem für Dengue Hämorrhagisches
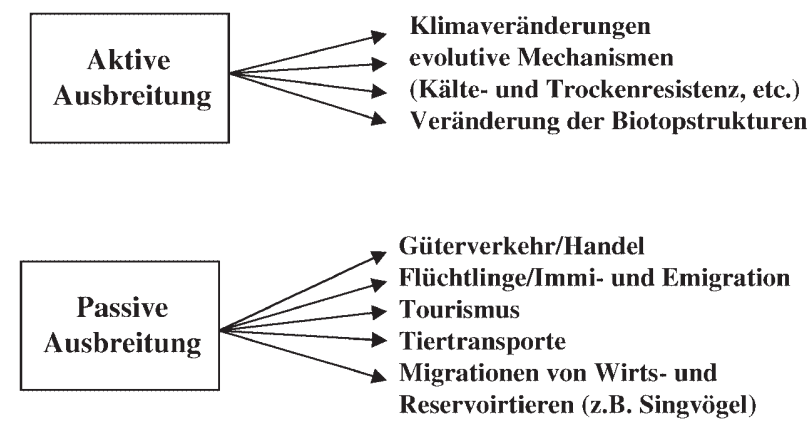

Abb. $1 \Delta$ Übersicht über die wichtigsten Ausbreitungsmechanismen und -faktoren 
Fieber, Rifttalfieber, Gelbfieber und Malaria auch aus Endemie- und Epidemiegebieten auf dem Luftweg weltweit verschleppt werden $[45,46]$. Das Verschleppungspotenzial von anderen vektorkompetenten Gliedertierordnungen wie Schild- und Lederzecken, Flöhe, Raubwanzen, Myiasiserreger etc. sind bislang nur wenig untersucht worden. Der Import von infizierten Nagetieren über Flugzeuge ist nach bisherigen Erkenntnissen und Erfahrungen jedoch eher selten. Während der Pestepidemie in Indien 1994 wurde allerdings einer von dort kommenden Maschine wegen einer Ratte an Bord der Weiterflug untersagt. Auch der Aspekt der Material- und Flugsicherheit bei Schadnagerbefall impliziert, dass zumindest ein kontinuierliches Monitoring auf vorliegenden Schadnagerbefall im Flugzeug notwendig ist [47]. Zur Verhütung der Einschleppung von Gliedertiervektoren über den Luftweg nach Deutschland werden seitens des Umweltbundesamtes seit etwa zwei Jahren Mittel und Verfahren zur Flugzeugdesinfektion mit dem Ziel der schnellstmöglichen Populationstilgung in Labor und Praxis geprüft [47], so dass in absehbarer Zeit auch hier eine Handlungsgrundlage für die Verhinderung der Einschleppung mit gefährlichen Erregern infizierter Vektoren gegeben ist. Bisher wird die Schädlingsbekämpfung in Flugzeugen nur ungenügend durchgeführt.

\section{Einschleppungen über den Schiffsverkehr}

Der Schiffsverkehr war seit jeher ein effektiver Verschleppungsweg für verschiedenste Vektoren und mit ihnen assoziierten Erregern. Die gefürchteten Gelbfieberepidemien, die vom 16. bis zum Anfang des 20. Jahrhunderts auf Schiffen und in klimatisch günstigen Seehäfen auch in Europa in großem Umfang ausbrachen, sind dafür ein gutes Beispiel [48]. Heute wird eine neue Ausbreitungswelle von vektorkompetenten Stechmücken beobachtet, die ihren Ursprung in Altreifenlieferungen hat. Im Verlaufe der letzen Dekade beispielsweise kam es zu einer Ansiedlung und Ausbreitung stabiler Populationen von Aedes albopictus, einem potenten urbanen Vektor für mehr als 20 humanpathogene Viren und von Ochlerotatus (Aedes) japonicus japonicus in den USA (wahrscheinlich auf dem Seeweg aus Asien eingeschleppt), von Aedes atropalpus und der nordamerikanischen kälteresistenten Variante von Aedes albopictus in Südeuropa (auf dem Seeweg über Altreifen mehrfach aus den USA eingeschleppt) und von Aedes albopictus in Nordaustralien (auf dem Seeweg aus Papua Neuguinea eingeschleppt).

Auch Nagetiere wie Ratten und Mäuse werden hauptsächlich auf dem Seeweg vor allem mit Nahrungsgütern verschleppt. Als Reservoir und Vektor der amerikanischen hämorrhagischen Fieber, des Lassafiebers und der verschiedenen Hantavirosen stellen insbesondere die stark kommensalen und/oder synanthropen Spezies, die aktiv das Umfeld oder die Nahrungsmittelvorräte des Menschen suchen, eine besondere Gefahr für die Einschleppung lebensbedrohender hochkontagiöser Infektionserreger dar. Da diese Tiere - und nicht nur die Hausmaus sowie die Haus- und Wanderratte - bevorzugt Nahrungs- und Futtermittel befallen, werden sie mit den globalen Handelslieferungen häufiger verschleppt (vgl. Tabelle 1).

In einigen Seehäfen befinden sich so genannte Einlassstellen, über die die aus Übersee stammenden Handelsgüter nach Deutschland eingeführt werden. Gemäß gültiger Planzenbeschau-Verordnung ist für den Bereich Pflanzenschutz dezidiert vorgeschrieben, welche Waren in den Einlassstellen auf welche Schädlinge untersucht werden müssen. Entsprechende Regelungen für den $\mathrm{Hy}$ gienebereich liegen derzeit nicht vor. In den Einlassstellen Emden und Wilhelmshaven werden z. B. jährlich jeweils über 100.000 t Getreide und Futtermittel aus Übersee eingeführt, die nicht beschaupflichtig nach Pflanzenschutzrecht sind, und daher auch nicht quarantänisiert oder auf Schädlingsbefall, z. B. auf hygienerelevante Nagetiere, untersucht werden. Sollte bei anderen, beschaupflichtigen Handelsgütern aus Übersee neben den eigentlich zu beprüfenden Holzund Pflanzenschädlingen ein Schadnagerbefall festgestellt werden, so liegt z. Z. keine Rechtsgrundlage für deren Bekämpfung vor [PD Dr. Lauenstein, Landwirtschaftskammer Weser-Ems, Oldenburg, persönliche Mitteilung]. Vergleichbares gilt für die Situation im Hamburger Hafen. Ein hoher Teil des dortigen Umschlags entfällt auf Container, von denen pro Jahr durchschnittlich 4 Mio. eingeführt werden. In den letzten Jahren sind die ca. 2 Mio. Tonnen Getreide, die pro Jahr eingeführt wurden, vermehrt als Schüttgut per Container umgeschlagen worden. Überwiegend aus Westafrika werden pro Jahr ca. 250.00o t Rohkakao eingeführt, die bis zum Eintreffen im Hamburger Hafen zwölf bis 16 Tage auf See waren. Eine vollständige Kontrolle durch die Behörden ist völlig unmöglich. Ein Import von hygienerelevanten Nagetieren kann zudem auch mit anderen Waren wie z. B. Textilien erfolgen [PD Dr. Schliesske, Universität Hamburg, Institut für Angewandte Botanik, Abt. Amtliche Pflanzenbeschau, Hamburg, persönliche Mitteilung]. Eine Einschleppung z. B. über Textilien und andere Handelsgüter halten die Nagetierexperten der Biologischen Bundesanstalt für Landund Forstwirtschaft insbesondere für Mäuse möglich, da diese bezüglich ihres Wasserbedarfes anspruchsloser sind als Ratten. Eine systematische qualitative und quantitative Untersuchung zum Einschleppungsrisiko von hygienerelevanten Schädlingen über den Seeweg nach Deutschland steht bislang noch aus. Über das Infektionsschutzrecht, den Hafenärztlichen Dienst und die entsprechenden Rechtssetzungen im Veterinärwesen allein ist daher eine wirksame Abwehr eingeschleppter, potenziell vektorkompetenter Nage- und Gliedertiere nicht möglich.

Im Rahmen zunehmender globaler Umweltveränderungen mit rapiden Urbanisierungstendenzen sind auch Gleichgewichtsveränderungen im epidemiologisch-infektiologischen Gefüge zwischen Reservoir, Vektor und Erreger zu analysieren und zu beachten [9]. So war das Argentinische Hämorrhagische Fieber in der Vergangenheit unbekannt, bis Farmer in der südamerikanischen Pampas im großen Maßstab Mais anbauten. Diese Biotopveränderung führte zu einer rapiden Populationszunahme von Calomys musculinus, der Reservoirmaus für das ursächliche Agens dieser Infektionserkrankung, dem Juninvirus, mit heute 100 bis 3500 Fällen pro Jahr [33]. Gründe für diese permanente Massenvermehrung der Tiere war einerseits der Rückgang der natürlichen Feinde, hauptsächlich Raubvögel, andererseits die Anlage kilometerlanger Maislager, die durch die kommensal gewordene Mausspezies im großen Umfang befallen wird [12]. Durch Maislieferungen aus diesen Regionen können interkontinental mit hoher Wahr- 
scheinlichkeit mit dem Juninvirus infizierte Calomys-musculinus-Mäuse auch nach Deutschland verschleppt werden.

Es gibt zudem Hinweise darauf, dass solche Einschleppungen tatsächlich vorkommen, denn anders lassen sich in Deutschland Funde der tropischen Rattenmilbe, Ornithonyssus bacoti, und anderer exotischer Ektoparasiten nicht erklären. Die Anwesenheit dieser Ektoparasiten fällt in aller Regel aber erst dann auf, wenn es zu einem merklichen Befall beim Menschen gekommen ist, wie z. B. durch eine ausgeprägte, Lindan-resistente Dermatitis bei sechs Studenten in Lübeck, die durch Ornithonyssus bacoti hervorgerufen wurde [49]. Systematisch wird dem Problem der Einschleppung hygienerelevanter Schädlinge, die Reservoire und/oder Überträger von humanpathogenen, auch gefährlichen Infektionserkrankungen darstellen können, in Deutschland gegenwärtig nicht nachgegangen. Überdies herrscht im Bereich des Gesundheits- und Veterinärwesens ein eklatanter Mangel an einschlägig epidemiologisch-entwesungstechnisch aus- bzw. fortgebildetem akademischen und technischen Personal.

\section{Infektionskettenunter- brechung}

Das Gesetz zur Verhütung und Bekämpfung von Infektionskrankheiten beim Menschen (Infektionsschutzgesetz-IfSG) ist durch Artikel 1 des Gesetzes zur Neuordnung seuchenrechtlicher Vorschriften (Seuchenneuordnungsgesetz) vom 20. Juli 2000 bekannt gemacht worden und am 1.1.2001 in Kraft getreten. Gleichzeitig wurde das ehemalige Bundes-Seuchengesetz außer Kraft gesetzt. Innerhalb des IfSG sind für die Bekämpfung vektorassoziierter Infektionskrankheiten des Menschen, so genannte Zooanthroponosen, die $\$ \$ 16,17$ und 18 von besonderem Interesse. Wenn Gesundheitsschädlinge festgestellt werden und die Gefahr begründet ist, dass durch sie Krankheitserreger verbreitet werden, so hat die zuständige Behörde, in aller Regel der Amtsarzt, die zu ihrer Bekämpfung nach dem Tilgungsprinzip erforderlichen Maßnahmen anzuordnen. Die für behördlich angeordnete Entseuchungen, Entwesungen sowie die Bekämpfung von Krankheitserreger übertragenden Wirbeltieren notwendigen Vorgaben sind dem $\S 18$ IfSG zu entnehmen.
Die jeweils gültige Fassung der geprüften und anerkannten Mittel und Verfahren zur Bekämpfung von tierischen Schädlingen nach $₫ 18$ IfSG wird im Bundesgesundheitsblatt bekannt gemacht. Die bisher letzte Novellierung dieser Liste, die sowohl die Entwesungsmittelliste als auch die Nagetierbekämpfungsmittelliste enthält, wurde im Jahr 2000 veröffentlicht [50]. Weiterhin können für den Menschen relevante Lücken auf dem Gebiet der Lebensmittelinfektionen, Toxikationen und Intoxikationen sowie Zooanthroponosen durch das Tätigwerden der dafür zuständigen Veterinärbehörde geschlossen werden. In aller Regel setzt sie ebenfalls Mittel und Verfahren der o.g. Liste ein. Diese Liste ist für die Behörden in vielen Bundesländern aufgrund verwaltungsrechtlicher Vorschriften verbindlich.

Wegen der angestrebten effektiven Infektionskettenunterbrechung im Seuchenfall erfolgen die Wirksamkeits- und Anwendungsprüfungen für Mittel und Verfahren nach $\$ 18$ IfSG nach dem Tilgungsprinzip und nicht, wie beispielsweise im Pflanzenschutz, nach dem Schadschwellenprinzip [9]. Die Prüfung nach $\$ 18$ IfSG setzt daher den schwierigsten Fall der Schädlingsbekämpfung im Gesundheitsbereich voraus, nämlich den Seuchenfall beim Menschen. Für derartige Infektionsfälle ist das Bekämpfungsziel die unverzügliche Eliminierung der beteiligten tierischen Vektoren am gleichen Ort zur gleichen Zeit unter Massenbefallsbedingungen. Die dabei auftretenden Auswirkungen auf die menschliche Gesundheit und die der Haustiere sowie auf die Umwelt müssen im Rahmen des Vertretbaren sein. Der einzelne Betroffene oder der ihn betreuende Arzt bzw. der seinen Tierbestand betreuende Tierarzt wäre mit der Durchführung einer solchen behördlichen, hochprofessionell auszuführenden Anordnung zur Entwesung oder zur Nagerbekämpfung mit dem Ziel der Verhinderung der Keimverbreitung oder -übertragung qualitativ und oft auch wirtschaftlich i.d.R. völlig überfordert. Durch das gewählte Verfahren der Infektionsbekämpfung muss sichergestellt sein, dass Entwesung, Nagetierbekämpfung und Desinfektion sich nicht gegenseitig blockieren und das die Erregerverschleppung aus dem Befallsherd unbedingt durch Vorsichts-, z. B. Desinfektionsmaßnahmen oder z. B. im Falle der urbanen Nagerpest durch Floh- bekämpfung vor der eigentlichen Nagetierbekämpfung, vermieden wird.

Der Einsatz von Mitteln und Verfahren nach $\S 18$ IfSG stellt also hohe medizinisch-zoologische, infektiologische, technische und rechtliche Anforderungen an die einschlägige Ausbildung und vor allem die Fortbildung der Amtsärzte, Gesundheitsaufseher und der gewerblichen und behördlichen Schädlingsbekämpfer. Dies trifft insbesondere dann $\mathrm{zu}$, wenn eingeschleppte, in Deutschland nicht endemische Reservoire und/oder Vektoren nach dem Tilgungsprinzip zu bekämpfen sind. Dann ist einerseits oftmals wenig über Bionomie und Transmissionsweg des Vektor-Erreger-Komplexes bekannt, was zu Problemen bei der exakten Definition der Infektionskette und deren Unterbrechung führen kann, andererseits sind gegen exotische, in Deutschland nicht vorkommende Gesundheitsschädlinge in der Regel keine Mittel und Verfahren nach $\$ 18$ IfSG geprüft und gelistet, weshalb hierbei meist Indikationslücken vorliegen. Bei Indikationslücken sollten die Gesundheitsschädlinge mit Mitteln und Verfahren bekämpft werden, die in Abstimmung zwischen den zuständigen Landesbehörden und den Mittelprüfinstitutionen (Umweltbundesamt und Bundesinstitut für gesundheitlichen Verbraucherschutz und Veterinärmedizin bzw. Bundesinstitut für Arzneimittel und Medizinprodukte) einvernehmlich für wirksam sowie in Bezug auf die Auswirkungen auf die Gesundheit und die Umwelt für vertretbar gehalten werden.

Besonders kritisch zu bewerten ist bei der Einschleppung von gefährlichen Infektionserregern über gebietsfremde Gesundheitsschädlinge die Zeit, die von der Befallskontrolle über die Anordnung der Bekämpfungsmaßnahmen nach $\$ 18$ IfSG, die Herstellung einvernehmlicher Definitionen über wirksame Mittel und Verfahren bei zu befürchtenden Indikationslücken, die Benennung im Seuchenschutz kompetenter Schädlingsbekämpfer bis zur Durchführung der eigentlichen Bekämpfungsmaßnahme zur Infektionskettenunterbrechung vergeht. Um diese Zeit kurz zu halten, wird dringend wenigstens eine Referenzstelle für die Risikobewertung und zumindest stichprobenartige Überwachung von Reservoirtieren bzw. Vektoren aus aktiven Endemie- oder Epidemiegebieten benötigt, die an ein Informationsnetz für Ge- 
sundheitsbehörden und kompetentes Bekämpferpersonal angeschlossen sein muss. Zudem ist das Vorhalten einer möglichst standardisierten Handlungsrichtlinie für Infektionsbekämpfungsmaßnahmen von Nagetierreservoiren und Überträgern importierter gefährlicher Infektionserreger u.a. für den schnellen und effizienten Einsatz von Mitteln und Verfahren nach oder analog zu $\$ 18$ IfSG unabdingbar. Ziel muss in jedem Fall die Befallstilgung sein, letztendlich auch, um eine anschließende Etablierung und Ausbreitung gebietsfremder Reservoirtiere und/oder tierischer Vektoren wirkungsvoll verhindern zu können. Dabei ist darauf zu achten, dass Menschen, Nichtzieltiere, Räume, Geräte und anderes Material sowie Freilandzielflächen nur im Rahmen vertretbarer Auswirkungen durch das Mittel, die Rückstände und/oder deren Zersetzungsprodukte belastet werden.

Dem Schädlingsbekämpfer/Desinfektor fällt trotz eines bestehenden guten hygienischen Umfeldes in Deutschland eine wichtige Aufgabe im Seuchenschutz $\mathrm{zu}$, die hohe Anforderungen an Wissen, Schutzvorkehrungen für die Mittelausbringer und die Zielraum- und Zielflächennutzer sowie an die Bekämpfungsstrategie stellt. Aufgrund ihrer beruflich bedingten Exposition gegenüber Nagetieren und Vektoren sowie bioziden Mitteln gehören sie einer Risikogruppe an, vor allem, da einige der genannten Infektionserreger wie z. B. die Hantaviren bereits endemisch sind [51]. Am Beispiel der Arenaviren, die hämorrhagische Fieber hervorrufen, wird deutlich, dass konsequente Infektionskettenunterbrechung nur durch Nagetierbekämpfung mit simultan durchgeführten Desinfektionsmaßnahmen bei gleichzeitiger Isolierung und Therapie von Erkrankten und Ansteckungsverdächtigen erfolgen kann. In diesem Zusammenhang ist es dringend erforderlich, dass die Schadnagerbekämpfung in enger Zusammenarbeit zwischen professionellen, durch die Industrie- und Handelskammer (IHK) geprüften Schädlingsbekämpfern und einem Desinfektor durchgeführt wird. Besser wäre noch die Doppelausbildung der im Teilgebiet „Gesundheitsschutz“ arbeitenden Schädlingsbekämpfer zum, ,Schädlingsbekämpfer/Desinfektor“.
Erfahrungen mit der Überschwemmungskatastrophe in der Oderregion im Juli und August 1997 zeigen, dass z. B. für die großflächige Bekämpfung von z. B. Stechmücken und deren Larven nach $\$ 18$ IfSG nicht genügend Mittel für den Katastrophenfall zur Verfügung stehen. Vorräte von Notfallpräparaten in ausreichend breiter Palette, wie sie von zahlreichen Staaten in einem zentralen, einer staatlichen Kontrolle unterliegendem Lager des Katastrophen- bzw. Zivilschutzes vorgehalten werden, sind in Deutschland nicht angelegt worden. Dieser Problematik der kurzfristigen Bereitstellung ausreichender Mengen tilgend wirksamer Vektorenbekämpfungsmittel für den Seuchenfall kann lediglich durch die nach Biozidrecht konzipierte, auf 120 Tage befristete Sonderzulassung der Biozide durch die zuständige Bundesoberbehörde entgegengewirkt werden.

\section{Fazit für die Praxis}

Ein Einschleppen lebensbedrohender und zugleich hochkontagiöser Infektionskrankheiten ist nicht nur durch den Menschen selbst, sondern vor allem auch durch tierische Primärwirte und Vektoren möglich. Es ist daher zwingend erforderlich, die kompletten Infektionsketten sowie das infektiologisch-ökologische Verhalten der Einzelkomponenten, d. h. des Erregers, der Primär- und ggf. Sekundärreservoire und des Vektors genau zu kennen bzw. wissenschaftlich zu untersuchen. Nur diese Kenntnis wird es erlauben, ein kontinuierliches qualitatives wie quantitatives Monitoring des Infektionsdruckes sowie im Seuchenfall eine entsprechend professionelle Infektionskettenunterbrechung gemäß Infektionsschutzgesetz durchführen zu können.

Während das Management sowie die Kontrolle durch den Menschen importierter hochkontagiöser Infektionserkrankungen ein funktionsfähiges Handlungsniveau erreicht hat, sind kontinuierliche Überwachungsmaßnahmen zur Verhinderung der Einschleppung von infizierten Naturreservoiren oder Vektoren über den Luft-, Land- und Seeweg nicht, noch nicht, oder nur marginal verfügbar. Die zeitkritische, sachgerechte und professionelle Anwendung von Nagetierbekämpfungs- und Entwesungsmitteln und -verfahren nach § 18 IfSG im Rahmen ange- ordneter antiepidemischer Maßnahmen, das Vorhalten ausreichend infektiologisch aus- und fortgebildeter Schädlingsbekämpfer und Desinfektoren sowie das Vorhalten ausreichender Mittelmengen im Falle von Großereignissen oder Katastrophen stellen derzeit ein weiteres Problem dar.

Mangels entsprechend medizinisch entomologisch-parasitologisch und vor allem tierisch-vektoriell arbeitender Referenzstellen und universitärer Einrichtungen sind die theoretischen und praktischen Erkenntnisse und Erfahrungen bei der Überwachung und Bekämpfung von vektorassoziierten Infektionserkrankungen in Deutschland relativ gering. Gleichzeitig ist das bis 1968 in Forschung und Lehre vertretene Fachgebiet der "Medizinischen Entomologie/Zoologie", das auch die wissenschaftliche Bearbeitung der „praktischen Vektorenbekämpfung“ und der „persönlichen Schutzmaßnahmen gegen Vektorenstiche bzw. -bisse" umfasst, derzeit durch deutsche Universitäten nicht mehr abgedeckt. Aufgrund der allgegenwärtigen globalen Ausbreitungstendenz von alten wie neuen Infektionserregern ist dies ein unhaltbarer Zustand.

Im Rahmen der Überwachung, Verhinderung, Minimierung und Bekämpfung vektorenübertragener Seuchengeschehen durch gefährliche hochkontagiöse Erreger müssen daher künftig eine kontinuierlich verfügbare Handlungsstruktur und die dazugehörige Logistik bereitgestellt werden. In diese muss die komplette Fachkompetenz, insbesondere von epidemiologisch-infektiologisch tätigen Humanmedizinern, medizinischen Entomologen, Veterinärmedizinern, Gesundheitsaufsehern, Schädlingsbekämpfern und Desinfektoren, integriert werden. Eine solche Struktur verlangt zunächst eine äußerst enge und kompatible Zusammenarbeit der verschiedenen Bundesoberbehörden wie z. B. des RKI, des UBA, des BgVV, aber auch der Bundeswehr sowie der Berufsverbände der Schädlingsbekämpfer und Desinfektoren. Für die praktische Umsetzung wiederum müssen Bekämpfungsrichtlinien, eine Liste mit ausreichend wirksamen Mitteln und Verfahren nach $\S 18$ IfSG sowie ausreichende Mengen von notwendigen Mitteln und Gerät vorgehalten werden. 


\section{Literatur}

1. Osterholm MT (2000) Emerging infections another warning. N Engl J Med 342:1280-1281

2. Lederberg J, Shope RE, Oaks SC (1992) Emerging infections: microbial threats to health in the United States. National Academy Press, Washington DC, USA

3. US National Intelligence Council (2000) The global infectious disease threat and its implications for the United States. http://www.cia.gov

4. Fock R, Wirtz A, Peters M et al. (1999) Management und Kontrolle lebensbedrohender hochkontagiöser Infektionskrankheiten. Bundesgesundheitsbl Gesundheitsforsch Gesundheitsschutz 42:389-401

5. Knobloch J (1999) Import gefährlicher Erreger. Internist 40:1157-1167

6. Fock R, Koch U, Wirtz A, Peters $M$, Ruf $B$, Grünewald T (2001) Erste medizinische und antiepidemische Maßnahmen bei Verdacht auf virales hämorrhagisches Fieber. Med Welt 52:126-132

7. Fock R, Koch U, Finke EJ et al. (2000) Schutz vor lebensbedrohenden importierten Infektionskrankheiten. Bundesgesundheitsbl Gesundheitsforsch Gesundheitsschutz 43:891-899

8. Fock R (1999) Zusammenarbeit ziviler und militärischer Institutionen auf dem Gebiet des Infektionsschutzes. Wehrmed Monatsschr 43 [Suppl]:3-7

9. Faulde M, Hoffmann G (2001) Vorkommen und Verhütung vektorassoziierter Erkrankungen des Menschen in Deutschland unter Berücksichtigung zoonotischer Aspekte. Bundesgesundheitsbl Gesundheitsforsch Gesundheitsschutz 44:116-136

10. Lindgren E, Talleklint L, Polfeldt T (2000) Impact of climatic change on the northern latitude limit and population density of the diseasetransmitting European tick Ixodes ricinus. Environ Health Persp 108:119-123

11. Faulde M, Sobe D, Kimmig P, Scharninghausen J (2000) Renal failure and hantavirus infection in Europe. Nephrol Dial Transplant 15:751-753

12. Fleischer K, Rieke B (1995) Neue Viruserkrankungen in den Tropen. Die gelben Hefte 35:124-130

13. Chin J (2000) Control of communicable diseases manual. American Public Health Association, Washington DC, USA

14. Anonymus (2000) Über den Schutz der Arbeitnehmer gegen Gefährdung durch biologische Arbeitsstoffe bei der Arbeit. Richtlinie 2000/54/EG vom 18.9.2000. Amtsblatt der Europäischen Gemeinschaften L 262:21-45

15. Khan AS, Young JC (2001) Hantavirus pulmonary syndrome: at the crossroads. Curr Opin Infect Dis 14:205-209
16. She JJ, Zhang Y, Huang CA (1998) A preliminary study on Leptotrombidium subpalpale as a vector of HFRS. Chinese J Vector Biol Control 9:47-50

17. Wu JW, Meng YC, Li YH, Zhou HF, Zhuge HX, Lai PX, Wang JMi (1998) Detection of HFRSV in Eulaelaps shanghaiensis and Ornithonyssus bacoti by using in situ hybridization. Chin J Parasit Parasit Dis 16:441-444

18. Hubalek Z, Halouzka J (1996) Arthropodborne viruses of vertebrates in Europe. Acta Sc Nat Brno 30:1-91

19. WHO (1998) Crimean-Congo hemorrhagic fever. Fact Sheet No. 208, December 1998. http://www.who.int/inf-fs/en/fact208.html

20. Hoogstraal H (1973) The epidemiology of tick-borne Crimean-Congo haemorrhagic fever in Asia, Europe and Africa.J Med Entomol 15:307-417

21. WHO (1998) An outbreak of Rift Valley Fever, Eastern Africa, 1997-1998. WER 73:105-109

22. Mellor PS, Leake CJ (2000) Climatic and geographic influences on arboviral infections and vectors. Rev Sci Tech Off Int Epiz 19:41-54

23. WHO (2000) Rift Valley fever in Yemen - Update 4. http://www.who.int/disease-outbreaknews/n2000/october/26october2000.html

24. WHO (2000) Rift Valley fever in Saudi Arabia Update 3.http://www.who.int/diseaseoutbreak-news/n2000/october/ 25october2000.html

25. ProMED (2001) Update on Rift Valley Fever Outbreak in Saudi Arabia. http://www. promedmail.org; Mailid=20010517.0964

26. ProMED (2000) Outbreak of Rift Valley Fever in Yemen, August - October 2000. http://www.promedmail.org; Mailid $=20001203.2106$

27. ProMED (2000) Rift Valley fever in Saudi Arabia.http://www.promedmail.org; Mailid $=20001007.1726$

28. Krauss $\mathrm{H}$, Weber A, Enders B, Schiefer HG, Slenczka W, Zahner H (1997) Zoonosen. Deutscher Ärzte-Verlag, Köln, S 165-166

29. Busygin FF (2000) Omsk hemorrhagic fever current status of the problem. Vopr Virusol 45:4-9

30. Liebisch A, Rahman MS (1976) Zum Vorkommen und zur vektoriellen Bedeutung der Zecken Dermacentor marginatus (Sulzer, 1776) und Dermacentor reticulatus (Fabricius, 1794) in Deutschland. Tropenmed Parasit 27:393-404

31. Zahler M, Gothe R (1997) Endemisierungsrisiko von Babesia canis durch Dermacentor reticulatus in Deutschland. Tierärztl Prax 25:666-670

32. Feldmann H, Slenczka W, Klenk H-D (1996) Emerging and reemerging of filoviruses. Arch Virol 11:77-100

33. Jahrling PB (1991) Filoviruses and Arenaviruses. Manual of Clinical Microbiology, 5 th edn. American Society for Microbiology, Washington DC, USA, Chap 97:984-997

34. Heymann DL, Szczeniowski M, Esteves K (1998) Re-emergence of monkeypox in Africa: a review of the past six years. Br Med Bull 54:693-702
35. Hutin YJ, Williams RJ, Malfait P et al. (2001) Outbreak of human monkeypox Democratic Republic of Congo 1996 to 1997. Emerg Infect Dis 7:434-438

36. WHO (2000) Plague. WHO report on global surveillance of epidemic-prone infectious diseases. WHO/CDS/CSR/ISR/2000.1:1-9, Genf, Schweiz

37. Schadewaldt H (1994) Die Rückkehr der Seuchen.VGS Verlagsgesellschaft, Köln, S 21-240

38. WHO (1999) Human plague in 1997.WER 74:340-344

39. Boisier $\mathrm{P}$, Rasolomaharo $\mathrm{M}$, Ranaivoson $\mathrm{M}$, Rasoamanana B, Rakoto L, Andrianirina Z, Chanteau S (1997) Urban epidemic of bubonic plague in Majunga, Madagaskar: epidemiological aspects. Trop Med Int Health 2:422-427

40. Turnbull PCB, Kramer JM (1991) Bacillus. Manual of clinical microbiology, 5 th edn. American Society for Microbiology, Washington DC, USA, Chap 33:296-303

41. Greenberg B (1973) Flies and disease, Vol.I. Ecology, classification and biotic associations, 1. edn. Princeton University Press, Princeton

42. Enserink M (2000) Malaysian researchers trace Nipah virus outbreak to bats. Science 289:518-519

43. Gratz NG (1999) Emerging and resurging vector-borne diseases. Ann Rev Entomol 44:51-75

44. Praetorius F, Altrock G, Blees N, Schuh N, Faulde M (2001) Acute renal failure after an unusual mode of transmission with falciparum malaria (,baggage malaria“). Nephrol Dial Transplant 16:628-630

45. Ellis RA (1996) Aircraft disinsection: a guide for military and civilian air carriers. AGARDAG-340, North Atlantic Treaty Organiszation, Brüssel

46. Gratz NG, Steffen R, Cocksedge W (2000) Why aircraft disinsection? Bull WHO 78:995-1004

47. Hoffmann $\mathrm{G}(2000)$ Gesundheitsschädlinge im internationalen Verkehr und deren Bekämpfung. Bundesgesundheitsbl Gesundheitsforsch Gesundheitsschutz 43:923-939

48. Hartmann V (1993) Gelbfieber an Bord. Schiff Zeit 41:46-52

49. Engel PM, Welzel J, Maass M, Schramm U, Wolff HH (1998) Tropical rat mite dermatitis: case report and review. Clin Infect Dis 27:1465-1469

50. Anonymus (2000) Bekanntmachung der geprüften und anerkannten Mittel und Verfahren zur Bekämpfung von tierischen Schädlingen nach § 10c Bundes-Seuchengesetz. Bundesgesundheitsbl Gesundheitsforsch Gesundheitsschutz 43 [Suppl 2]:62-74

51. Faulde M (1996) Die Hantavirus-Infektion: Gefahr und Herausforderung für den Schädlingsbekämpfer? DpS 48:16-21 